I Universidade Federal do Rio Grande do Sul (UFRGS), Programa de Pós-Graduação em Antropologia Social, Porto Alegre, RS, Brasil guilherme_bartz@hotmail.com https://orcid.org/oooo-0002-3804-6130

I I Universidade Federal do Rio Grande do Sul (UFRGS), Programa de Pós-Graduação em Antropologia Social, Porto Alegre, RS, Brasil ruben.oliven@gmail.com

\title{
COMO O TRABALHO FLEXÍVEL AFETA OS MÚSICOS ERUDITOS? O CASO DA OROUESTRA DE CÂMARA THEATRO SÃO PEDRO DE PORTO ALEGRE
}

\section{INTRODUÇÃO}

A flexibilização do trabalho é realidade que atinge número cada vez maior de profissões. No setor artístico, um dos segmentos que vêm sendo mais afetados por essa configuração é o da música, especialmente o setor formado pelos profissionais que atuam no campo da música erudita. Nesse ramo, muitos músicos trabalham de forma descontinuada, tendo que adotar múltiplas frentes de trabalho para poder enfrentar a incerteza econômica e a falta de garantias profissionais. Este artigo analisa essa realidade a partir de um caso concreto: os músicos da Orquestra de Câmara Theatro São Pedro (OCTSP), grupo sediado em Porto Alegre, no Rio Grande do Sul.

Esses profissionais foram estudados a partir de uma pesquisa etnográfica. A combinação da observação direta dos ensaios e dos concertos com entrevistas individuais possibilitou captar a dinâmica da orquestra e o cotidiano dos músicos com foco nas relações de trabalho.

A etnografia que embasa este artigo foi realizada com os músicos da orquestra entre dezembro de 2016 e agosto de 2017 , e consistiu na observação de 22 ensaios e dez apresentações do conjunto. Também foram feitas I 6 entrevistas individuais, incluindo I5 instrumentistas e o maestro. É importante frisar que os profissionais que participaram da pesquisa obtinham toda a sua renda desempenhando atividades exclusivamente vinculadas ao campo da música. 
Ainda que o foco da etnografia tenha sido sobre a participação dos músicos no contexto da OCTSP, também buscamos examinar todas as demais formas de atuação profissional desses indivíduos, seja como instrumentistas de outras orquestras ou professores de música, seja como músicos de eventos (casamentos, formaturas, aniversários, homenagens, funerais) ou em outras atividades musicais. Essa ampla variedade de estratégias de atuação profissional é reveladora, principalmente, da grande flexibilidade, informalidade e precariedade que caracteriza esse setor específico de trabalho.

$\mathrm{O}$ artigo tem três seções, seguidas de uma conclusão. A primeira seção oferece considerações teóricas, a partir de Boltanski e Chiapello (2009), sobre a flexibilidade e a precarização do trabalho num contexto geral. A segunda, apoiada em Menger (I999, 2005), examina esse fenômeno de forma mais explícita: no universo artístico. A terceira seção apresenta os resultados da etnografia com os músicos da orquestra, que revelaram as particularidades dessa flexibilidade e as implicações dessa condição em suas vidas, tanto no âmbito profissional quanto fora dele. Por último, a conclusão explicita certas contradições observadas nas relações de trabalho dos músicos e aponta novas possibilidades de pesquisa nesse setor específico do mercado de trabalho.

\section{TRABALHO FLEXÍVEL E PRECARIZAÇÃO}

Uma boa parte do trabalho musical na atualidade, especialmente no contexto da música erudita, vem sendo marcada pela flexibilidade, a atuação por projetos, ${ }^{\mathrm{I}}$ os múltiplos empregos, a incerteza econômica e a falta de garantias profissionais por parte dos trabalhadores. Essas características não são atributos exclusivos da atividade musical, nem mesmo da atividade artística entendida num sentido amplo. Antes, relacionam-se a contextos mais extensos: são configurações que vêm sendo observadas há algumas décadas e que atingem uma série de setores do mundo do trabalho, em níveis globais. Essas novas conformações, percebidas dentro do que se poderia chamar de um novo espírito do capitalismo (Boltanski \& Chiapello, 2009), possuem origem histórica definida e certas peculiaridades que merecem ser elucidadas. O trabalho, tal como o entendemos hoje, nem sempre ocorreu dentro dos moldes atuais - em especial o trabalho artístico e o musical. Por essa razão, torna-se relevante compreender como essas mudanças tiveram curso.

Boltanski e Chiapello (2009) são sociólogos que ajudam no entendimento desse cenário de transformações no mundo do trabalho. De acordo com eles, a partir dos anos I 980 muitas empresas adotaram como estratégia, em relação a seus trabalhadores, aquilo que veio a ser denominado flexibilidade. Esse termo pode ser explicado a partir de dois enfoques. Primeiro, verifica-se uma flexibilidade interna nas empresas, com base em profunda transformação da organização do trabalho: uma exigência devida à polivalência do trabalhador, que precisa desenvolver seu autocontrole, sua autonomia etc. Segundo, perce- 
be-se uma flexibilidade externa, que supõe uma organização do trabalho em rede, na qual as empresas encontram os recursos de que carecem por meio de abundante subcontratação e de mão de obra maleável em termos de emprego (empregos precários, temporários e trabalho autônomo), de horários e de jornada de trabalho (em tempo parcial, com horários variáveis etc.) (Boltanski \& Chiapello, 2009: 240).

Com o passar dos anos, conforme essas mudanças foram sendo implementadas pelas empresas, observou-se que inúmeros trabalhos se tornaram cada vez mais precarizados. Os vínculos entre os trabalhadores e as empresas fragilizaram-se, já que muitos contratos de emprego passaram a ser feitos dentro da lógica flexível: por um tempo determinado, parcial e variável - fator que impactou diretamente a confiança e segurança do empregado em relação a seu emprego. Essa tendência veio se acentuando tanto nas últimas décadas, que, em alguns setores, o que era a exceção de antigamente tem-se transformado na regra atual: a forma normal e mesmo aceitável de trabalho, em diversos segmentos, vem seguindo o modelo da flexibilidade. ${ }^{2}$

Quando surgiram, essas mudanças foram acompanhadas, não sem alguma ironia, de uma "propaganda positiva". Elas nasceram (e ainda aparecem) vinculadas a uma ideia de libertação do trabalhador, conceito originalmente associado a uma crítica ao capitalismo. No entanto, com o tempo, essa ideia desvirtuou-se, passando a representar um novo tipo de exploração do trabalhador.

$\mathrm{Na}$ esteira dessas mudanças, observou-se também um culto ao desempenho individual e uma exaltação da mobilidade do trabalhador (Boltanski e Chiapello, 2009: 239). Os profissionais mais valorizados passaram a ser aqueles que apresentavam alto rendimento produtivo e grande versatilidade em sua forma de atuação. Uma palavra que ganhou força, e que também carregava consigo a intenção de dissimular as novas desigualdades do mundo do trabalho, foi empregabilidade. Esse termo designa a capacidade que as pessoas precisam ter para que a elas se recorra nos projetos (Boltanski e Chiapello, 2009: I 26). Defende-se que a experiência que se conquista na atuação em múltiplos projetos é uma oportunidade para aumentar a própria empregabilidade - que também pode ser entendida como uma espécie de capital pessoal que cada um deve ter e gerir, sendo constituída pela soma de inúmeras competências.

Essas e outras transformações no mundo do trabalho acabaram sendo acompanhadas de forte degradação da situação de muitos trabalhadores. No que se refere à condição financeira e à estabilidade profissional, é importante ressaltar que a posição social de inúmeras pessoas sofreu reveses significativos. Para Boltanski e Chiapello (2009: 279), no que diz respeito aos salários, parece que cada vez mais estão sendo desvinculados desses pagamentos os custos incorridos antes do emprego (gastos com formação, sustento durante os períodos de inatividade, folgas etc.) e depois dele (reconstituição das forças, desgaste e enve- 
lhecimento etc.). Os pagamentos estão cada vez mais atrelados apenas ao tempo efetivamente trabalhado, o que corresponde a um ajuste quase em tempo real, por parte das empresas, entre os gastos, o número de empregados e a demanda pelos serviços (Boltanski \& Chiapello, 2009: 272).

Essa nova forma de exploração dos trabalhadores, que beneficia empresas e empregadores, encontra pouca resistência por parte dos prestadores de serviço, porque o medo difuso do desemprego, associado à forte concorrência, é fator que neles estimula certa "docilidade". Para poder continuar "jogando o jogo", dentro das regras atualmente vigentes, as pessoas são pressionadas a aceitar essas novas relações trabalhistas, pouco podendo fazer para mudar a situação em que se encontram.

\section{O TRABALHO NO CONTEXTO ARTí́stico}

Pierre-Michel Menger é um sociólogo francês que se vem debruçando sobre o tema do trabalho no âmbito artístico. Segundo seu entendimento, a classe dos artistas caracteriza-se pelos seguintes atributos:

no seio da população ativa, os artistas são mais jovens, mais instruídos, mais concentrados nas metrópoles, conhecem taxas mais elevadas de trabalho independente assim como de desemprego e de subemprego involuntário (devido à forte difusão das diferentes formas de trabalho a tempo parcial e de trabalho intermitente), e são muito frequentemente pluriativos. Os seus ganhos são em média inferiores aos dos ativos da sua categoria de pertença - os "quadros e profissionais intelectuais superiores" em França, os "professionals, technical and managerial workers" nos EUA. Os seus rendimentos são por outro lado mais variáveis de um período a outro da sua carreira, e as desigualdades interindividuais de rendimento são ao mesmo tempo particularmente elevadas e paradoxalmente muito bem aceitas (Menger, 2005: 17).

O autor ressalta que as formas de emprego por meio das quais os artistas oferecem seus serviços são em geral o autoemprego, o freelancing e as diversas formas atípicas de trabalho (trabalho intermitente, trabalho em tempo parcial e multiassalariado). Isso tem como efeito introduzir nas situações individuais de atividade a descontinuidade; as alternâncias entre períodos de trabalho, desemprego e procura de atividade; a gestão de redes de interconhecimento e de sociabilidade fornecedoras de informações e de compromissos; a multiatividade na e/ou fora da esfera artística etc.

De acordo com Menger (2005: I09), o mundo artístico desenvolveu quase todas as formas flexíveis de emprego, ou seja, diversas modalidades de exercício do trabalho (desde o mais estreitamente subordinado até o mais autônomo) e diferentes combinações de atividade (da pluriatividade escolhida pelo criador de sucesso à pluriatividade forçada do criador que financia o seu trabalho através de atividades de subsistência).

Isso não quer dizer que trabalhos ditos estáveis não sejam encontrados nesse setor. Ocorre que serviços desse tipo tendem a se concentrar em locais 
específicos, principalmente em organizações artísticas com atuação sólida e permanente, tais como orquestras sinfônicas, casas de ópera, conservatórios e empresas de arquitetura (Menger, I999: 546). Ainda assim, essas mesmas organizações costumam combinar, em seu quadro de funcionários, uma parte de trabalhadores estáveis com uma parcela de prestadores de serviços com vínculos temporários. Observando-se organizações culturais menores ou de atuação mais efêmera, contudo, percebe-se que há um predomínio dos contratos de trabalho de curto e médio prazos.

Seguindo a lógica da flexibilidade, os contratos de trabalho firmados entre trabalhadores e contratantes possibilitam criar laços e despedir os primeiros de acordo com as conjunturas e necessidades momentâneas, sem grandes prejuízos para os segundos. Essa situação é, paradoxalmente, muito semelhante à observada em setores nos quais os trabalhadores são pouco qualificados - já que a simplicidade das tarefas que eles realizam permite rápida substituição da mão de obra em caso de necessidade. Nesses outros mercados, ditos secundários, os trabalhadores costumam ter pouca qualificação e formação, por isso recebendo salários baixos (Menger, I999: 546).

Apesar de semelhante, entretanto, a situação no contexto artístico apresenta algumas distinções interessantes. Esse é um setor no qual as diferenças entre os trabalhadores são extremamente valorizadas: de talento, experiência, aparência física etc. (Menger, 2005: I02). Além disso, como classe, os artistas costumam ter formação e qualificação superiores aos dos trabalhadores secundários. ${ }^{3}$ É nesse ponto que surge o paradoxo: os artistas são trabalhadores qualificados e relativamente bem remunerados (como ocorre nos mercados primários), mas atuam sob um regime de grande flexibilidade de emprego (como verificado nos mercados secundários).

Ao seguir a lógica da flexibilidade, as organizações artísticas beneficiamse enormemente dessa configuração porque, num cenário de desintegração vertical da produção, elas podem minimizar seus riscos, transferindo a incerteza do mercado para baixo, ou seja, diretamente para os trabalhadores (Menger, I999: 550). Os artistas tornam-se, na realidade, trabalhadores independentes que ficam circulando entre os vários empregos disponíveis. Eles acabam atuando como "operadores de pequenos negócios", realizando transações com organizações maiores e, muitas vezes, participando de forma esporádica e simultânea em múltiplas frentes de trabalho.

Ainda que assimétrica, essa relação entre empregados e empregadores se tornou a forma predominante que ambos os lados encontraram para, juntos e de forma interdependente, poder atuar. Nesse sentido, o artista acaba muitas vezes se tornando um empresário de sua própria carreira, um portfolio worker, "a custo de uma forte individualização do seu sistema pessoal de atividade e de uma gestão racionalizada dos seus capitais pessoais (tempo, esforço, competências, empregabilidade, reputação)" (Menger, 2005: I 22). 
No que se refere aos contratantes, percebe-se como é do interesse das organizações poder contar sempre com um leque de profissionais competentes e (quase sempre) disponíveis, que possam constituir equipes capazes de oferecer um serviço de qualidade. Os empregadores, desse modo, ficam livres para recorrer ou não a indivíduos que conhecem e com os quais já trabalharam (o que representa segurança), e também deixam em aberto a possibilidade da descoberta de novos talentos (o que constitui uma aposta, mas sem grandes riscos, já que os vínculos podem ou não ser firmados, conforme o interesse dos contratantes) (Menger, 2005: I06-I07).

Diante dessa configuração, constata-se que o lado mais frágil da negociação, ou seja, o lado representado pelos artistas, é aquele que mais sofre com as incertezas e as flutuações econômicas, sobretudo no que se refere à renda. Ao se considerar a carreira de um único artista, com frequência é possível observar alterações nos ganhos econômicos ao longo dos anos, discrepâncias essas também verificadas quando se comparam os rendimentos de diversos artistas de um mesmo setor.

Essa grande insegurança financeira e profissional experimentada pelos artistas acaba se refletindo tanto em termos práticos quanto emocionais. O sentimento de incerteza e dúvida em alguma medida parece acompanhar todos aqueles artistas que não possuem vínculos estáveis em sua forma de atuação profissional. É claro que alguns indivíduos são mais afetados que outros, tanto emocionalmente quanto em sua atividade prática diária. Quanto menos um artista possuir garantias de que irá obter trabalho ou que conseguirá se manter permanentemente empregado, mais fortes serão os efeitos negativos dessa insegurança.

Menger (I999: 550) ressalta que quanto mais talentoso ou habilidoso for um artista, quanto melhor for sua reputação e quanto maior e mais qualificada for sua rede de contatos (bons relacionamentos interpessoais no meio profissional), mais chances esse indivíduo terá de obter trabalhos. Isso acaba gerando monopólios, nos quais um certo número de artistas domina determinados setores de atuação. Em contrapartida, artistas mais novos e em início de carreira ou que não preenchem satisfatoriamente as características acima mencionadas tendem a formar uma população periférica que sofre mais diretamente com a insegurança profissional. Estando à margem do mercado de trabalho, algumas parcelas de trabalhadores enfrentam maior descontinuidade de atuação e taxa de desemprego mais elevada.

A fim de combater tais incertezas, tanto em termos práticos quanto emocionais, uma palavra-chave para os artistas é a conquista de uma boa reputação. Esse conceito relaciona-se diretamente com o de empregabilidade, posto que ter boa reputação influencia diretamente as chances de obter trabalhos. Como empresários de suas próprias carreiras, os artistas precisam constantemente manter elevada reputação no intuito de conquistar boas oportuni- 
dades de atuação. A reputação, em geral, não é algo que se conquista da noite para o dia: antes, é resultado da atuação do profissional ao longo dos anos, sendo um capital acumulável (Menger, 2005: 85-86) que funciona como uma espécie de currículo que o artista exibe.

A reputação também é elemento importante a ser levado em conta no que se refere à circulação dos profissionais pelos vários trabalhos. Isso porque um artista que tenha um "bom nome" no meio e que seja reconhecido por cumprir bem suas tarefas acaba sendo mais requisitado por aqueles que detêm o poder de contratar. Como para cada projeto a opção costuma ser, na maior parte dos casos, pelos profissionais com certa "garantia de qualidade", geralmente acabam sendo empregados aqueles que reconhecidamente mais se destacam.

No meio artístico, ambiente que em geral se caracteriza por forte concorrência profissional, a reputação surge como um capital pessoal que o artista deve cultivar e gerir. Caso contrário, se cair em descrédito (por motivos diversos), sempre há o risco de um artista ter suas oportunidades de trabalho bastante limitadas. Nesse sentido, observa-se como a lógica da flexibilidade possibilitou a emergência de novas formas de valorização e distinção dos trabalhadores, em meio às quais a empregabilidade e a reputação aparecem como instâncias de destaque.

\section{O TRABALHO NO ÂMBITO DA MÚSICA ERUDITA: OS MÚSICOS DA OR- QUESTRA DE CÂMARA THEATRO SÃO PEDRO}

A investigação sobre as condições de trabalho dos músicos da Orquestra de Câmara Theatro São Pedro (OCTSP), conjunto musical sediado em Porto Alegre, Rio Grande do Sul, possibilitou traçar um panorama do modo como ocorre a atuação de profissionais nesse mercado de trabalho específico. Os resultados obtidos refletem um caso particular, mas, em alguma medida, também podem ser generalizados para outras instâncias. A etnografia teve como foco um grupo de músicos que se mantinham unidos pelo fato de atuar numa mesma orquestra, cujo caso, entretanto, sem dúvida espelha uma realidade comum a muitos músicos eruditos brasileiros e de outros países, indivíduos que possuem condições de trabalho semelhantes, em vários aspectos. Antes, porém, de abordar a condição desses artistas, é relevante descrever brevemente a própria orquestra.

\subsection{A Orquestra de Câmara Theatro São Pedro (OCTSP)}

Fundada em I985, a Orquestra de Câmara Theatro São Pedro tem como sede, como seu nome indica, o Theatro São Pedro, prédio histórico inaugurado em I 858 e localizado no Centro Histórico de Porto Alegre. A OCTSP é uma das cerca de dez orquestras que atualmente existem no Rio Grande do Sul, sendo uma das mais tradicionais e importantes devido a suas mais de três décadas de atuação continuada. Como a maioria desses conjuntos, é um grupo de nível 
profissional em que atuam majoritariamente músicos graduados e não apenas estudantes de música - como outras orquestras de menor projeção do estado.

O surgimento da OCTSP ocorreu graças a uma parceria informal entre a direção do Theatro São Pedro e o Departamento de Música da Universidade Federal do Rio Grande do Sul (UFRGS). Inicialmente, a proposta era formar uma orquestra jovem que atuasse naquele teatro. O objetivo era permitir que os estudantes de música se apresentassem ao público e projetassem sua futura carreira. Com o passar dos anos, contudo, a OCTSP profissionalizou-se, deixando de empregar apenas estudantes de música para aceitar, em seu quadro, principalmente instrumentistas já diplomados.

Apesar de, desde o início, realizar seus ensaios e apresentações nas dependências do Theatro São Pedro e mesmo levando o nome do próprio teatro, a OCTSP não se encontra atrelada a essa instituição; apresenta autonomia em sua direção, possuindo diretoria e CNPJ próprios. Ao contrário do que muitos acreditam, a OCTSP não é da Secretaria da Cultura nem do estado do Rio Grande do Sul, não recebendo diretamente verba pública. A orquestra não possui vínculo jurídico com o Theatro São Pedro, mas sim vínculo afetivo - já que, em certo sentido, é a única produção feita exclusivamente no espaço físico do teatro.

A diretoria da OCTSP é formada por três dirigentes (um empresário, um advogado e um músico), que contam com o apoio de outros profissionais encarregados da direção-geral, coordenação financeira, coordenação administrativa e assessoria de comunicação. Um único músico exerce o cargo de diretor artístico e maestro da orquestra.

Ao longo de sua existência, a OCTSP contou com importantes patrocinadores ${ }^{4}$ que garantiram temporadas estáveis e continuadas de apresentações. Até poucos anos atrás, a diretoria conseguia planejar, com segurança, as atividades da orquestra para o ano inteiro - o que hoje em dia é quase impossível, visto que o grupo não dispõe mais de investimentos tão substanciosos.

A OCTSP é formada por cerca de 20 músicos, ${ }^{5}$ dos quais um terço é do sexo feminino e dois terços são do sexo masculino. A média de idade dos profissionais é de 35 anos. Há instrumentistas que estão na orquestra há bastante tempo, alguns com mais de dez, I 5 ou 20 anos de atuação, às vezes sem interrupção. Muitos começaram na orquestra quando ainda cursavam a faculdade de música ou eram recém-formados e a ela continuam ligados até hoje. Outros entraram no grupo há pouco tempo, um ou dois anos apenas.

O conjunto é essencialmente constituído por músicos que tocam instrumentos da família das cordas: violinos, violas, violoncelos e contrabaixos. Eventualmente, outros instrumentistas também são convidados a integrar o grupo, tais como madeiras, metais, percussão etc. Na época da pesquisa, a OCTSP procurava contemplar três séries de concertos, cada uma com uma proposta, repertório e público distintos. ${ }^{6}$ Os cachês que os músicos recebiam para tocar em cada concerto, independentemente da série, estavam em torno de mil reais.? 
Desde sua criação, a OCTSP é mantida com o apoio exclusivo da iniciativa privada. Para se sustentar, a orquestra depende diretamente das leis de incentivo à cultura. Seu funcionamento está, pois, atrelado à captação de recursos externos - o que pode resultar em atuação continuada ou descontinuada, dependendo das circunstâncias. Nesse sentido, é importante invocar Segnini (20 I I: 73-74), que ressalta, no caso brasileiro, o fato de que nas últimas duas ou três décadas se tem revelado crescente a participação de grandes empresas no financiamento do setor artístico, graças ao incentivo das próprias políticas públicas.

A participação do capital privado vem sendo estimulada e regulada, nesse setor, por meio da Lei Federal de Incentivo à Cultura (Lei no 8.8I3/9I), conhecida como Lei Rouanet. Ela define as bases da política de relações entre o Estado e o capital privado, a partir da renúncia fiscal para o investimento em cultura. Em outras palavras, são recursos públicos direcionados para a área da cultura, distribuídos conforme a capacidade de diferentes grupos apresentarem projetos de acordo com as exigências dos patrocinadores. Desde I997, as empresas podem deduzir de seu imposto sobre a renda até ı०o\% do valor incentivado $^{8}$ em projetos culturais. Nos estados e municípios, a lei de incentivo à cultura, por meio da isenção fiscal, também é reproduzida (Segnini, 20I I: 75).

É importante assinalar que essas novas políticas culturais, que aos poucos foram sendo implementadas no Brasil, impactaram em cheio algumas orquestras e seus músicos, obrigando-os a passar por repentinas adaptações. Ao longo dos anos, verificou-se uma redução sistemática dos postos de trabalho formais nas orquestras, justificada por argumentos econômicos e artísticos. Reconhece-se, nesse processo, uma influência de políticas neoliberais e privatizadoras. Segnini (2014: 77) destaca que:

As orquestras sinfônicas, pouco a pouco e não sem conflitos, foram transforma-
das, por meio da ação do próprio Estado, em fundações e organizações sociais,
capazes de captar recursos privados para o desenvolvimento de seus programas
artísticos. Nesse processo, algumas orquestras foram fechadas e outras reestru-
turadas. Isso quer dizer que seus músicos foram submetidos a audições, que
redundaram em demissões e novas contratações, não mais de acordo com o
Estatuto dos Funcionários Públicos, conforme determina a Constituição Federal
de I988, mas na qualidade de trabalhadores temporários ou celetistas.

Essas transformações não tiveram influências diretas sobre a OCTSP, pois desde o seu surgimento esse conjunto foi mantido exclusivamente pela iniciativa privada. Como a orquestra depende das leis de incentivo à cultura para captar recursos junto às empresas privadas, os músicos da OCTSP não possuem salário fixo: recebem de acordo com a participação nos concertos. ${ }^{9}$ $\mathrm{Na}$ época da pesquisa, sua diretoria estava sempre às voltas com dificuldades financeiras, procurando patrocinadores a fim de manter a orquestra em funcionamento. O ritmo de atuação da orquestra, portanto, era diretamente pautado pela captação desses recursos. 
Embora o foco da etnografia tenha sido sobre a participação dos músicos na OCTSP, ao longo da pesquisa foram também consideradas todas as outras formas de atuação desses profissionais: como instrumentistas de outras orquestras, professores de música e como músicos de eventos (casamentos, formaturas, aniversários, homenagens, funerais) etc. Essas múltiplas formas de atuação profissional revelam, evidentemente, o alto nível de flexibilidade, informalidade e precariedade que marca esse setor de trabalho.

\title{
3.2. A flexibilidade do trabalho do músico erudito e as implicações dessa condição
}

Em primeiro lugar, é importante frisar que os 16 músicos da orquestra entrevistados (os I5 instrumentistas e o maestro) obtinham toda a sua renda desempenhando atividades exclusivamente vinculadas ao campo da música, ou seja, nenhum deles tinha um emprego ou trabalho paralelo em outro setor. Como seus rendimentos oriundos da OCTSP não eram suficientes para seu pleno sustento econômico, viam-se obrigados a recorrer a outras fontes de renda. O trabalho que eles desempenhavam na OCTSP nem sempre representava sua principal fonte de arrecadação: antes, era apenas mais uma das várias atividades que exerciam poderia ser a principal ou não, dependendo de cada caso. Numa das entrevistas, ao abordar esse tema um dos músicos reclamou do excesso de atividades:

\begin{abstract}
Na semana passada eu estava tocando em três orquestras ao mesmo tempo. Teve um dia que eu tive ensaio o dia todo e um concerto de noite. Eu não queria entrar no palco, queria ir embora para casa. Meu corpo se negava a tocar, de tanto cansaço. Ser músico não é uma atividade fácil, é sofrido. Que profissão difícil que fui escolher! A gente trabalha em casa também... Tem que estudar, sempre levamos trabalho para casa. Financeiramente falando, se o músico toca em apenas uma orquestra, não tem como sobreviver. O músico precisa, pelo menos, tocar em duas ou três orquestras, ou também dar aulas, tocar em eventos... O músico sempre vai trabalhar muito para ganhar o necessário.
\end{abstract}

Uma particularidade da pesquisa foi que todos os músicos entrevistados, em sua atuação como performers, trabalhavam sob o sistema de cachês, ou seja, ganhavam parte de sua renda (ou toda ela) de acordo com a participação em projetos (concertos com orquestras, trabalho em eventos etc.). Num quadro mais geral, pode-se dizer que esses profissionais se localizavam mais à margem de um núcleo central de trabalhadores que também atuam no mesmo setor e que possuem vínculos trabalhistas mais sólidos (carteira assinada, vínculo estatutário etc.). Como consequência, pode-se afirmar que os nossos interlocutores sofriam mais que estes últimos com os efeitos negativos decorrentes da instabilidade profissional. Alguns músicos revelaram:

A instabilidade me incomoda. É algo muito complicado. Tem que estar sempre com um olho na frente. Se eu sei que nesse mês não haverá concerto numa orquestra, já tenho que tentar buscar alguns eventos para tocar, casamentos, ou cachês em outras orquestras... Tem que ir se virando. 
Tem orquestras que oferecem uma certa estabilidade, mas outras não. Isso é chato, a gente nunca sabe o que vai acontecer.

Nesse sentido, é importante ressaltar que todos os instrumentistas afirmaram que prefeririam ter um emprego seguro e estável em vez de trabalhos incertos e instáveis, nos moldes dos que vinham desempenhando. Apesar de parecer óbvia, essa resposta unânime é reveladora do grande descontentamento em relação à situação em que eles se encontravam:

Eu preferiria ter um trabalho estável, com salário fixo. Meu trabalho, por ser incerto, traz muitos problemas e preocupações. Espero um dia ter um trabalho estável, poder tocar numa orquestra de forma fixa e regular, até para poder ganhar mais e conseguir concretizar meus planos de vida.

Se eu tivesse que escolher entre um trabalho estável e um instável, eu escolheria um estável, pela estabilidade financeira, como é nas grandes orquestras, como a OSPA. ${ }^{\text {Io }}$

Eu acho que o salário da OSPA é um salário bom, mas não é todo músico que consegue chegar ali. Estando lá é possível ter uma dedicação exclusiva, viver somente daquilo. Nos outros casos a gente tem que tocar em duas orquestras, aceitar outros cachês, fazer outras coisas para poder ter um padrão de vida melhor. Eu preferiria trabalhar em apenas uma orquestra, fixo, tendo a segurança desse trabalho e desse salário, para poder me dedicar só a isso, por mais que eu fosse sentir falta da variedade de trabalhos. Mas a segurança financeira pesaria mais.

Eu preferiria ter um trabalho regular. Quero uma estabilidade para mim. Acho que nenhum músico vai dizer que gosta de tocar por cachê, que quer viver a vida toda fazendo isso. A busca é sempre pela estabilidade profissional.

Para seguir atuando como músicos, muitos indivíduos precisam adotar múltiplas frentes de trabalho. Em primeiro lugar, cerca de dois terços dos instrumentistas entrevistados relataram que, além dos ganhos econômicos oriundos da OCTSP, obtinham cachês tocando em outras orquestras do estado. Esses músicos eram constantemente convidados para concertos em duas, três ou mais orquestras. A inserção desses profissionais em vários grupos lhes possibilitava uma certa segurança econômica, pois existia uma expectativa de que sempre surgiria alguma oportunidade de trabalho. Como as datas dos ensaios e apresentações entre os grupos nem sempre coincidiam, em geral eles podiam aceitar mais de um compromisso ao mesmo tempo. Esses músicos circulavam entre várias orquestras. Alguns entrevistados revelaram que obtinham toda a sua renda atuando somente como músicos de orquestra.

Outros interlocutores, entretanto, trabalhavam também em outras atividades musicais, dentre as quais se destacava a docência. Alguns eram professores em escolas de música, outros davam aulas em projetos sociais, e outros, ainda, possuíam alunos particulares (havia aqueles que recebiam alunos em casa e/ou que iam até a casa dos alunos para ministrar as aulas). Nenhum entrevistado disse ser professor em colégio - apesar de essa ser outra possibi- 
lidade de atuação profissional. Assim, a menos que fizessem algum tipo de "contrato formal" com seus alunos, ou que fossem músicos contratados em escolas de música, a docência também aparecia como uma atividade que não oferecia muitas garantias profissionais. Isso porque, a qualquer momento, o aluno pode desistir das aulas, ou a escola de música pode dispensar o professor, já que em muitos casos este é encarado como um profissional autônomo.

Outra forma de ganhar dinheiro é o que se poderia chamar de atuação em eventos: casamentos, formaturas, eventos empresariais, aniversários, homenagens, funerais etc. Dentro dessa categoria ampla, há trabalhos percebidos como mais ou menos prestigiosos, que pagam melhor ou pior etc. Para conseguir uma inserção sólida nesses diferentes segmentos profissionais, todavia, é fundamental constituir uma boa rede de contatos, formada por clientes e colegas que possam indicar trabalhos. Também é importante conhecer outros músicos que estejam dispostos a constituir duos, trios, quartetos etc. quando necessário. Comparando-se o número de horas trabalhadas com o valor do cachê normalmente cobrado, o trabalho em eventos, por exemplo, costuma ser mais vantajoso que o trabalho em orquestras. Trabalha-se menos e se ganha mais. Mesmo assim, é comum que muitos músicos mesclem ambas as atividades no intuito de aumentar sua renda e reputação.

Por fim, outras formas pelas quais os músicos podem obter dinheiro são os recitais que eles eventualmente oferecem (apresentações solo ou em pequenas formações instrumentais), bem como os cachês oriundos da gravação de trilhas sonoras, CDs e DVDs. Estes últimos trabalhos, todavia, tendem a ser esporádicos para a maioria dos músicos. O dinheiro arrecadado com a apresentação de recitais nem mereceria ser contabilizado porque grande parte desses eventos é gratuita, e aqueles nos quais é cobrado ingresso acabam não proporcionando retornos econômicos relevantes. Os cachês decorrentes da participação em gravações são mais rentáveis, mas são oportunidades de trabalho que não costumam aparecer com muita frequência.

É claro que, se todas essas opções musicais se revelarem insuficientes ou mesmo inviáveis, o músico, para sobreviver, em último caso ainda pode atuar em outra área não relacionada à música. No entanto, isso geralmente só é feito em circunstâncias de muita necessidade. A maioria dos entrevistados revelou que nunca havia trabalhado em outro setor, mas um ou outro comentou que, no passado, já teve algum emprego não artístico (em padaria, loja de ferragem etc.), embora fossem atividades desempenhadas antes da opção, em definitivo, pela carreira musical.

Dentro dessa gama de atividades, há trabalhos que compensam mais pelo lado financeiro, enquanto outros valem a pena muito mais pelos retornos imateriais que proporcionam. As preferências por tipo de trabalho variam de acordo com cada indivíduo, que pode priorizar fatores econômicos ou artísticos, dependendo das circunstâncias e necessidades. Independentemente de como 
essa escolha seja orientada, contudo, existe uma série de pontos que os músicos precisam cuidar para que sua empregabilidade se mantenha sempre elevada: reputação, manutenção de nível técnico (habilidade, talento) acima da média, boa rede de contatos, competência no exercício da atividade, confiança dos outros em seu trabalho etc.

Ainda no que diz respeito ao tema da flexibilidade trabalhista, um ponto de destaque que surgiu ao longo da etnografia refere-se aos impactos psicológicos negativos da condição desses profissionais. De modo geral, observa-se forte sentimento de insegurança, desconfiança e intranquilidade. Como os empregadores não são "diretamente" responsáveis pela carreira dos artistas, estes muitas vezes se sentem à deriva, com poucas garantias profissionais. A indefinição econômica que o músico erudito experimenta ao longo da carreira - já que ele dificilmente pode prever quando surgirão trabalhos/projetos - acaba lhe gerando forte inquietação e pressão psicológicas, bem como um acentuado estresse emocional. Dificilmente o músico pode antever como estará sua situação financeira em médio e longo prazos. Alguns integrantes da OCTSP foram bastante eloquentes quando falaram a respeito dessa condição desfavorável:

Eu, sendo músico hoje, não sei como será minha vida daqui a um ou dois anos. Não sei se terei a mesma estabilidade de poder continuar tocando nas mesmas orquestras que eu toco hoje. Não sei se continuarei tendo o mesmo retorno financeiro ou não. Não sei se vou ter que buscar outros caminhos, profissionalmente, além de tocar em orquestras. O meu objetivo é continuar sendo um músico de orquestra, mas eu não sei realmente como será daqui para frente.

Às vezes não é possível se planejar, pois não tem como saber como será a realidade no futuro. Eu, por exemplo, tenho planos de vida, mas não tenho a mínima ideia se eles vão se concretizar ou não. Isso é algo ruim. É preciso se acostumar com isso, saber que os planos que temos nem sempre poderão se concretizar. Pode ser que agora eu esteja tocando numa orquestra, e daqui duas semanas mudar completamente o número de concertos. Então eu precisarei buscar outros recursos para poder me manter financeiramente, seja tocando em casamentos, fazendo cachês em outras orquestras, buscando mais alunos...

A próxima semana, por exemplo, eu não sei o que vou ter de concertos. O que aparece de oportunidades eu vou aceitando. Para amanhã terei um trabalho que até uns dias atrás eu não estava esperando. Eu não tenho uma estabilidade. Isso afeta minha rotina diária. Nunca sei como será o meu dia a dia. Em longo prazo, é pior ainda. Eu não posso fazer muitos planos, já que pode ser que nada se concretize. Tu nunca sabes como será a tua condição financeira no final do mês, então tem sempre que estar fazendo reserva financeira ou mantendo uma poupança. Há meses em que nenhum trabalho aparece, e a gente não consegue prever isso. Tem meses em que há muitos trabalhos, que pagam bem. Em outros meses simplesmente cortam tudo e tu não sabes como vai ser. Por melhor que eu esteja vivendo hoje, isso não é garantia de nada para depois. Isso afeta tudo: planos, parte financeira, família, amigos... 
Diante de tantas incertezas sobre o próprio trabalho, alguns músicos procuram fugir da instabilidade profissional ambicionando uma vaga num grupo musical que ofereça carteira assinada, ou então buscando uma aprovação num concurso público para alguma orquestra. Tornar-se um músico concursado é o objetivo principal de carreira de vários instrumentistas, pois um emprego desse tipo proporciona as garantias que eles tanto almejam.

No contexto gaúcho, foi possível perceber, a partir da etnografia, que a meta de emprego de vários instrumentistas que pretendem seguir atuando como performers é a Orquestra Sinfônica de Porto Alegre. Em termos de salário e de garantias profissionais, essa é a orquestra que mais se destaca, pois se trata de uma fundação pública estadual, administrada sob forma autárquica, que estabelece um vínculo estatutário com seus músicos. Os concursos de admissão de novos músicos, porém, só ocorrem a cada quatro ou cinco anos e costumam ser bastante concorridos, atraindo candidatos de todo o Brasil e até de outros países. O último concurso, realizado no final de 20I4, teve 27 músicos aprovados nos mais variados instrumentos, dentro de um universo de mais de 550 candidatos (isto é, a média era de 20 concorrentes por vaga).

A maioria dos 15 instrumentistas entrevistados havia prestado esse concurso, tendo três sido aprovados. Na época da pesquisa de campo, contudo, eles ainda não haviam sido oficialmente chamados para assumir os cargos, mas pouco antes do final de 2017 houve a tão aguardada nomeação. O plano desses músicos, para o ano seguinte, era dedicar-se exclusivamente à OSPA.

Assim, escapariam do regime flexível, uma condição que os obrigava a seguir uma lógica temporal que em muitos casos era bastante caótica. Nessa configuração, o trabalho tende a ser pouco ordenado temporalmente, não possuindo um padrão muito estruturado, característico de outras profissões, por exemplo. Existe grande variabilidade de horários, o que pode ser, por um lado, um fator positivo e, por outro, negativo.

Os aspectos positivos, conforme relatado nas entrevistas, relacionam-se ao fato de haver várias opções para poder montar a agenda de compromissos, de acordo com as próprias preferências individuais. Em outras palavras, o profissional pode jogar como bem quiser com o tempo que tem disponível. É claro que muitos músicos não têm a opção de escolher todos os seus horários de trabalho (os ensaios e apresentações de orquestra são exemplos de compromisso "fixos"), mas muitas atividades podem ser negociadas (como as aulas particulares).

Entretanto, às vezes se torna muito difícil conciliar todas as diversas atividades A flexibilidade e a informalidade trazem também uma série de problemas incontornáveis. Frequentemente os artistas precisam realizar verdadeiros malabarismos com o tempo dedicado ao trabalho (desmarcando e remarcando compromissos, recusando ofertas de serviços por falta de espaço na agenda, lamentando os dias ociosos em que poderiam estar exercendo alguma 
atividade etc.). A maioria dos trabalhos que surgem não é oferecida para se encaixar perfeitamente na agenda dos músicos: eles, sim, precisam ajustar-se da melhor forma possível para conseguir cumprir com qualidade as tarefas.

É interessante, ainda, explorar a questão dos monopólios que surgem como consequência da concorrência dentro dos meios artísticos, monopólios que, aliás, também resultam da flexibilidade trabalhista. Como já mencionado, manter uma boa rede de contatos, ao menos no que se refere àqueles músicos mais impactados pela instabilidade profissional, é importante em vários sentidos (não apenas para a manutenção de um posto de trabalho numa orquestra, por exemplo). Ter vínculos com outros músicos é relevante porque esses colegas podem fazer indicações de trabalhos tais como eventos, aulas ou até mesmo substituições em orquestras.

É claro que, dentro da lógica da troca de dádivas, quando um músico indica outro para um serviço desse tipo, ele espera que o favor seja retribuído quando surgir uma oportunidade. Essa troca de gentilezas acaba fortalecendo as redes. Um músico que possua vários contatos e, mais do que isso, contatos de qualidade, tem menor possibilidade de se ver em apuros econômicos devido à falta de trabalho. Conforme essas redes vão se fortalecendo, surgem verdadeiros monopólios que dominam certos setores de atuação profissional. As próprias orquestras podem ser encaradas como uma espécie de monopólio, pois há grupos que são tão fechados, que músicos de fora não conseguem entrar.

É nesse sentido que se pode tomar emprestada a noção de "panelinhas", apresentada por Becker (2008: I I3-II4) ao escrever a respeito dos músicos de jazz e dos músicos comerciais, universo que foi por ele etnografado:

Uma rede de "panelinhas" informais, interligadas, distribui os empregos disponíveis num dado momento. Para obter trabalho em qualquer nível, ou para avançar até os empregos num novo nível, a posição que uma pessoa ocupa na rede é de grande importância. As "panelinhas" são unidas por laços de obrigação, os membros apadrinham-se uns aos outros na obtenção de empregos, seja contratando-se uns aos outros quando têm poder para tanto, seja recomendando-se uns aos outros para aqueles que fazem as contratações para uma orquestra. A recomendação é de grande importância, pois é assim que indivíduos disponíveis tornam-se conhecidos pelos que contratam; a pessoa desconhecida não será contratada, e o pertencimento a essas "panelas" assegura a um músico que ele tem muitos amigos que o recomendarão para as pessoas certas. Assim, o pertencimento às "panelas" proporciona emprego estável ao indivíduo.

Obviamente, quanto mais à margem desses monopólios ou "panelinhas" estiver um artista, maior será a sua instabilidade profissional, já que mais dificuldades ele enfrentará para mostrar aos outros a qualidade e o valor de seu trabalho. A forte concorrência gerada pela flexibilidade trabalhista acaba ensejando o estabelecimento de formas protetivas alternativas. Os trabalhadores, quando podem, buscam apadrinhar-se uns aos outros, protegendo-se contra ameaças externas, isto é, contra outros músicos que possam lhes tomar o es- 
paço.

Valores sociais como amizade, companheirismo e simpatia, por exemplo, por vezes podem sobrepujar as qualidades artísticas propriamente ditas do profissional (habilidade técnica, musicalidade, disposição e vontade para o trabalho, talento etc.) no que se refere à contratação para algum trabalho. Em outras palavras, aqueles que são empregados nem sempre são os melhores músicos (num sentido estritamente técnico), mas sim aqueles indivíduos que possuem bons relacionamentos interpessoais e uma boa rede de contatos.

No caso da OCTSP, o maestro era a pessoa que detinha o poder de determinar quem fazia parte da orquestra e quem ficava de fora do grupo. Ele também nomeava os músicos que assumiriam os postos mais relevantes dentro do conjunto (spalla e líderes de naipe). Em consequência disso, os instrumentistas esforçavam-se para sempre manter um bom relacionamento com o regente. Mas não apenas isso: eles precisavam se dar bem com os outros colegas, a fim de fortalecer os laços profissionais, constituindo assim uma boa rede interna de contatos que os ajudava na manutenção do emprego.

\subsection{Reflexões sobre a flexibilidade do trabalho no universo da música erudita}

Este artigo tem como propósito de investigação os profissionais da música erudita que sofrem mais diretamente com as situações de flexibilidade/mobilidade, instabilidade, precariedade e informalidade nesse setor específico de trabalho. A orquestra pesquisada, justamente por ser formada exclusivamente por instrumentistas que atuam a partir do sistema de cachês, revelou-se um ambiente propício e fecundo para a compreensão dessas realidades profissionais.

É muito difícil achar um "culpado" para a situação desses músicos: não estamos sugerindo, nesse ponto, que a OCTSP devesse ser responsabilizada pela condição em que esses profissionais se encontram. Isso porque, como já relatado, o próprio funcionamento e existência da OCTSP dependem exclusivamente da captação de recursos externos, que podem surgir ou não, de acordo com as circunstâncias. Preferimos inverter a perspectiva: vemos a OCTSP como mais uma oportunidade de trabalho para esses músicos, e isso é algo positivo para eles.

Ao longo da pesquisa, foi possível observar que a situação flexível de trabalho nem sempre é percebida como algo negativo por todos os músicos desde que os trabalhos existam, é claro. Há indivíduos que gostam de trabalhar em vários segmentos diferentes, dentro deste grande campo denominado mercado da música. Eles se sentem livres para direcionar sua carreira segundo seus próprios interesses, sem tantas obrigações para com um único empregador ou local de trabalho. Para esses músicos tal situação apresenta seus próprios benefícios e vantagens. Isso, entretanto, se torna um problema para aqueles profissionais que não se sentem confortáveis diante dessa configuração. Há indi- 
víduos que são obrigados a desempenhar múltiplas atividades porque, se não o fizerem, não conseguirão se sustentar economicamente, ao menos não de forma compatível com suas expectativas.

Muitos dos entrevistados tinham como perspectiva ou expectativa de vida o trabalho exclusivo como músicos de orquestra. Como a realidade do mercado de trabalho não lhes permitiu essa atuação direcionada, foram forçados a assumir outras ocupações, a buscar alternativas; por isso dão aulas, tocam em eventos de todos os tipos etc. Não fazem isso por vocação ou por gosto, mas porque precisam complementar a renda. Esses indivíduos, no fundo, são obrigados a adotar uma flexibilidade profissional que não lhes convêm. Isso é revelador de um verdadeiro drama social do trabalho (Dubar, 2005: I49), no qual os trabalhadores precisam desempenhar tarefas que não desejam por uma questão de sobrevivência econômica.

Além de suscitar certo desgosto, a necessidade de atuar em múltiplas frentes de trabalho tende a gerar uma queda no rendimento do músico, especialmente quando se considera a função principal que ele gostaria de estar exercendo. Ao trabalhar com diferentes atividades, o artista acaba, no fundo, não se aperfeiçoando ou se especializando em nenhuma, muito menos no segmento em que ele de fato gostaria de se envolver - seja por falta de tempo ou mesmo de disposição física e mental, já que os outros trabalhos acabam lhe consumindo muita energia.

O músico erudito, nos dias de hoje, diante das configurações observadas no mundo do trabalho artístico, parece viver numa situação de plena liberdade - é a propalada "liberdade do trabalhador", que aparece associada à propaganda positiva em torno da flexibilidade trabalhista. Em muitos sentidos, ele é realmente livre para escolher os trabalhos que mais lhe agradam, os projetos mais convenientes para sua participação. $O$ fato de não estar amarrado a um único empregador sem dúvida lhe traz uma série de vantagens, e é interessante constatar que, na história da música, tal situação nem sempre foi assim.

A liberdade na atuação artística é algo que veio sendo conquistado aos poucos, pelos próprios artistas. Foi um processo que se desenvolveu ao longo dos séculos. Nesse sentido, é interessante fazer referência à história de Wolfgang Amadeus Mozart (I756-I79I), um dos mais consagrados compositores da música clássica, indivíduo que lutou com todas as suas forças, ao longo da vida, pela obtenção de sua liberdade criativa e de atuação profissional (Elias, I995).

Contudo, essa mobilidade ou versatilidade na atuação do músico, quando em excesso (como parece estar se tornando a regra hoje), acaba sendo não uma libertação, mas algo que oprime o artista. Isso porque o músico se vê colocado num contexto de mercado de trabalho no qual tudo pode acontecer, e ele dificilmente consegue fazer previsões a respeito de como será seu futuro. Sem conseguir firmar raízes em local algum, encontra muitas dificuldades para direcionar sua carreira para um único objetivo ou finalidade. Ao não tecer vín- 
culos estáveis com nenhum empregador, os profissionais realmente se veem livres para fazer o que bem quiserem, mas essa liberdade excessiva em certa medida acaba os enclausurando. Se quiserem aceitar trabalhos, eles podem; se quiserem negá-los, também podem. São livres, mas sem nenhuma garantia.

A situação social e de trabalho do músico, ao longo dos tempos, passou por um processo de reversão em sua própria essência. Mozart ansiava poder sobreviver como artista liberto, sem depender diretamente dos mandos e desmandos da aristocracia. Muitos músicos hoje - todos os nossos entrevistados, pelo menos -, contudo, desejam o oposto disso: querem adquirir estabilidade no emprego, vínculos mais fortes com os seus empregadores, pois assim terão a garantia de sobrevivência econômica adequada a suas necessidades.

A liberdade associada ao contexto da flexibilidade é enganosa em vários níveis. Em primeiro lugar, o músico muitas vezes não é "realmente livre" para escolher os trabalhos que vai desempenhar. Dependendo do local em que reside e atua, bem como do contexto artístico no qual está inserido e da demanda que existe por seus serviços, o artista pode se ver na obrigatoriedade de aceitar qualquer oportunidade que apareça, independentemente da qualidade dos trabalhos oferecidos. Na verdade, em muitos momentos o músico acaba não podendo escolher. A ideia da liberdade do trabalhador, sob esse ângulo, também é algo que precisa ser relativizado.

Outro ponto é que, ao mesmo tempo em que estimula uma atuação em múltiplas frentes de trabalho, a flexibilidade pode ser também um fator limitador dessa mesma atuação. Muitos músicos precisam negar bons trabalhos devido a compromissos já assumidos, ou então cancelar boas oportunidades de ganhar dinheiro na expectativa de acordos já firmados que, no fim, acabam não se concretizando. Além disso, muitas ofertas de trabalho nem sempre resultam em trabalho realmente cumprido, já que pode haver inúmeras colisões de horários entre as diversas oportunidades de prestação de serviços.

A propaganda positiva em torno da flexibilidade do trabalho e do trabalhador também oculta o fato de que muitas atividades possuem certa sazonalidade. Não são todos os trabalhos que aparecem com regularidade ou periodicidade, já que alguns serviços costumam ocorrer apenas em certas épocas do ano. Tocar em formaturas e casamentos, por exemplo, são eventos que se concentram em meses específicos. Da mesma forma, em janeiro e fevereiro as atividades musicais costumam apresentar um decréscimo significativo: as orquestras interrompem sua atuação, muitos alunos param de fazer aulas porque viajam de férias etc.

A soma de todos esses fatores e outros mais faz com que os músicos se sintam bastante inseguros em relação a suas possibilidades e oportunidades de trabalho. Não é tanto no sentido de que não haverá nenhum trabalho por um tempo muito prolongado, mas sim no que diz respeito à regularidade, qualidade e rentabilidade desses serviços. Boa parcela dos músicos nunca tem 
plenas garantias de que estará trabalhando, pois, assim como alguns meses podem ser lucrativos, outros podem não render praticamente nada. As garantias em geral são quase sempre de curto prazo. Em médio e longo prazos, quase não há como prever o que pode acontecer.

Dos 5 instrumentistas entrevistados na pesquisa, somente um possuía carteira assinada como músico de outra orquestra. Só ele, portanto, tinha garantias (mínimas, mas importantes - pois sempre há o risco de ser despedido) de que teria férias remuneradas, décimo terceiro salário, seguro desemprego, horas extras, adicional noturno, fundo de garantia etc. Quanto aos outros I4, o sentimento de dúvida e insegurança era grande. A estratégia normalmente adotada pela maioria deles era a de aproveitar ao máximo as oportunidades de trabalho durante o ano para, nos meses mais difíceis, ter algum dinheiro guardado para pagar as despesas. Em caso de necessidade, costumavam pedir auxílio econômico aos familiares ou ao cônjuge.

\section{CONCLUSÃO}

Esta pesquisa mostra que a fronteira que separa o emprego do desemprego nunca é muito bem delimitada no segmento do mercado de trabalho dos músicos eruditos, já que ela varia de acordo com os meses do ano e ao longo da própria carreira do profissional. Nessa situação, na qual abundam os frágeis vínculos trabalhistas e a informalidade, percebe-se que os músicos na realidade acabam circulando entre vários trabalhos e atividades. As oportunidades precisam ser aproveitadas ao máximo, pois nunca se pode ter certeza de que haverá outras melhores no futuro, ou mesmo se tais chances irão aparecer.

Se essa situação já é difícil para músicos com certa experiência de carreira, o que dizer daqueles indivíduos que estão entrando no mercado de trabalho? É importante frisar que muitos músicos em início de carreira, recémgraduados na faculdade, encontram muitas dificuldades para conseguir um emprego porque as vagas disponíveis já estão, em sua maioria, ocupadas. É o caso do segmento do mercado de trabalho representado pelas orquestras.

As redes de contato (os monopólios e "panelinhas") que marcam a atuação dos instrumentistas nesse setor, ao mesmo tempo em que garantem serviço para aqueles que delas participam, também impedem a entrada de novos profissionais. Os indivíduos que não fazem parte dessas redes - por ainda não ter contatos bem firmados com pessoas que possam lhes oferecer oportunidades de trabalho (incluindo também aqueles indivíduos que, por diversos motivos, tenham sido excluídos dessas redes) - não encontram espaço sequer para mostrar suas habilidades, qualidades e competências. Nesse sentido, as redes acabam gerando, ao mesmo tempo, situações de inclusão e exclusão profissional.

Por fim, oferecemos duas últimas observações. Primeiro, o fato de o trabalho no setor musical ser bastante marcado pela flexibilidade e pela ausência de vínculos formais de emprego não significa que, na prática, seja essa a rea- 
lidade sempre observada. O que pode existir, na verdade, são tentativas de um não reconhecimento dos vínculos trabalhistas. Ressalta-se, nesse sentido, um aspecto contraditório: é certo tratar um músico como um profissional autônomo (em orquestras ou em outros setores) quando, em muitos casos, são sempre os mesmos indivíduos que são contratados?

A relação formal de trabalho estipulada em muitos contratos acaba não reconhecendo um tipo de vínculo de emprego que, no fundo, realmente existe e pode ser, aliás, bastante sólido. Há músicos que assinam contratos de trabalho como se estivessem participando de serviços pontuais e esporádicos, sendo que, na prática, seu desempenho é fixo e regular. Acreditamos que seria preciso olhar para tal situação com mais atenção.

A segunda observação refere-se ao fato de que, na pesquisa, foram entrevistados músicos eruditos que, bem ou mal, vinham conseguindo trabalhar na área - ainda que estando um pouco à margem de um mercado de trabalho que se poderia chamar de mais central, por assim dizer. Entretanto, certamente não são esses os profissionais que se localizam mais na periferia do setor. $O$ que dizer daqueles profissionais que obtêm trabalhos apenas de maneira mais esporádica do que aqueles? O que falar dos artistas que sofrem mais diretamente com o desemprego? E daqueles músicos que não encontram muitos trabalhos porque não conseguem manter suas empregabilidade e reputação muito elevadas? Seria interessante realizar pesquisas com esses outros segmentos de artistas, trabalhadores que certamente estão ainda mais sujeitos aos reflexos negativos da flexibilidade, instabilidade, precariedade e informalidade que marcam esse setor específico do mercado de trabalho.

A atual fase do capitalismo tem sido fortemente caracterizada pela flexibilização do trabalho, uma realidade que vem atingindo número cada vez maior de profissões. Esse processo manifesta-se nos mais variados setores da economia e causa insegurança profissional e pessoal em meio a diversos tipos de trabalhadores. Como mostra a pesquisa que embasa este artigo, a flexibilização também vem ocorrendo entre músicos eruditos que, na falta de um emprego fixo, precisam desenvolver diversas estratégias de atuação profissional. Embora, em diferentes períodos históricos, a vida dos músicos eruditos sempre apresentasse o desafio da sobrevivência econômica, na atualidade eles enfrentam novas dificuldades em muitos aspectos semelhantes aos obstáculos que marcam, há muito mais tempo, a atuação de profissionais de outras áreas.

Recebido em 20/6/20I8 | Revisto em 2I/I2/20I8 | Aprovado em 2I/I/20I9 
Guilherme Furtado Bartz é graduado em música (bacharelado em composição) pela UFRGS (2008); graduado em comunicação social (bacharelado em jornalismo) pela PUCRS (2OI I); e mestre em antropologia social pela UFRGS (20I8). Atualmente, é doutorando em antropologia social pela UFRGS.

Ruben George Oliven, doutor pela Universidade de Londres, é professor titular do Programa de Pós-Graduação em Antropologia Social da UFRGS, pesquisador IA do CNPq e membro da Academia Brasileira de Ciências. É autor de vários livros, entre eles A parte e o todo: a diversidade cultural no Brasil-nação, agraciado com o Prêmio de Melhor Obra Científica de Ciências Sociais do Ano e traduzido para o espanhol e o inglês. Recebeu o Prêmio Érico Vannucci Mendes por sua contribuição ao estudo da cultura brasileira e o Prêmio Anpocs de Excelência Acadêmica em Antropologia. 


\section{NOTAS}

I Neste artigo, entende-se projeto, no contexto musical, como qualquer tipo de trabalho com duração definida. Os projetos podem variar desde a participação do músico num único evento (tocando num casamento, por exemplo), até um convite para que o profissional participe de um concerto com uma orquestra, ou mesmo a contratação do músico para uma temporada de concertos. No primeiro caso, o projeto é de curtíssimo prazo (pois o esforço do músico se limita a poucas horas de trabalho); no segundo caso, é de curto prazo (geralmente demandando uma semana de trabalho, já que o músico precisa comparecer aos ensaios da orquestra e ao concerto propriamente dito); no terceiro caso, o projeto pode ser de médio ou longo prazo (uma vez que o músico pode ser contratado pela orquestra por um mês, um semestre, um ano etc.). Já que curto e longo são adjetivos bastante subjetivos, eles são utilizados aqui apenas para ilustrar uma possível classificação temporal das diferentes modalidades de projeto.

2 Os recentes debates, no Brasil, em torno da Reforma Trabalhista e da Lei da Terceirização reforçam essa percepção.

3 Ainda mais quando se considera o caso dos músicos eruditos, cujo grau de formação costuma ser elevado.

4 Dentre os quais se podem destacar as empresas Gerdau, Olvebra, Ipiranga e Banco Itaú.

5 O número de integrantes varia de acordo com as circunstâncias de cada espetáculo. Não existe um grupo fechado de instrumentistas, ainda que na prática seja possível observar certas regularidades: há músicos que poderiam ser classificados como tendo uma atuação mais permanente no grupo e outros com vínculos mais esporádicos.

6 Os Concertos Oficiais primam pela música erudita, contemplando obras que abarcam do período barroco ao século XXI; os Concertos Banrisul para Juventude são didáticos, mistura de aula e espetáculo, e têm como meta a divulgação da música orquestral para estudantes de escolas públicas do ensino fundamental; e os Concertos Dominicais desenvolvem a proposta de integrar a música erudita com a música popular brasileira (vocal e instrumental) por meio de arranjos e releituras orquestrais. 
7 Esses mil reais contemplavam tanto as horas trabalhadas na apresentação quanto o tempo despendido nos vários ensaios que antecediam o concerto propriamente dito.

8 O valor incentivado é limitado a $4 \%$ do imposto de renda devido pela pessoa jurídica e $6 \%$ pela pessoa física, conforme os artigos I8, $\S \S$ I $^{\circ}$ e $2^{\circ}$, e 26 da Lei 8.3I3/9I, bem como os artigos 28,29 e 30 do Decreto n $576 \mathrm{I} / 2006$ e o artigo I3, § $2^{\circ}$, da Lei $9.249 / 95$.

9 Os músicos da OCTSP nunca tiveram carteira de trabalho assinada.

Io Orquestra Sinfônica de Porto Alegre (OSPA).

\section{REFERÊNCIAS BIBLIOGRÁFICAS}

Becker, Howard Saul. (2008). Outsiders: estudos de sociologia do desvio. Rio de Janeiro: Jorge Zahar.

Boltanski, Luc \& Chiapello, Ève. (2009). O novo espírito do capitalismo. São Paulo: Martins Fontes.

Dubar, Claude. (2005). A socialização: construção das identidades sociais e profissionais. São Paulo: Martins Fontes.

Elias, Norbert. (I995). Mozart, sociologia de um gênio. Rio de Janeiro: Jorge Zahar.

Menger, Pierre-Michel. (2005). Retrato do artista enquanto trabalhador: metamorfoses do capitalismo. Lisboa: Roma Editora.

Menger, Pierre-Michel. (1999). Artistic labor markets and careers. Annual Review of Sociology, 25, p. 54I-574.

Segnini, Lilian Rolfsen Petrilli. (20I4). Os músicos e seu trabalho: diferenças de gênero e raça. Tempo Social, revista de sociologia da USP, 26/I, p. 75-86.

Segnini, Lilian Rolfsen Petrilli. (20II). O que permanece quando tudo muda? Precariedade e vulnerabilidade do trabalho na perspectiva sociológica. Caderno CRH, 24/esp. I, p. 69-86. 


\section{COMO O TRABALHO FLEXÍVEL AFETA OS MÚSICOS ERUDITOS? O CASO DA ORQUESTRA DE CÂMARA THEATRO SÃO PEDRO DE PORTO ALEGRE \\ Resumo}

A flexibilização do trabalho atinge também o campo da música erudita. Muitos músicos atuam por projetos e têm múltiplos empregos, lidando com a incerteza econômica e a falta de garantias profissionais. Este artigo analisa os músicos da Orquestra de Câmara Theatro São Pedro, localizada em Porto Alegre e mantida somente com recursos privados, mostrando que eles sobrevivem exclusivamente de atividades ligadas ao campo da música, por meio dos cachês que recebem pelos concertos e pela atuação em outros serviços musicais. Mediante pesquisa etnográfica que incluiu assistência a ensaios e concertos, bem como entrevistas, foi possível mostrar como a flexibilização do trabalho afeta os artistas que se inserem nesse segmento do mercado de trabalho musical.

\section{HOW DOES FLEXIBLE LABOUR AFFECT CLASSICAL MUSICIANS? THE CASE OF THE SÃO PEDRO THEATRE CHAMBER ORCHESTRA OF PORTO ALEGRE}

Abstract

Labour flexibilization also affects the field of classical music. Many musicians work on a project-basis and have multiple jobs, having to cope with economic uncertainty and the lack of professional guarantees. This article analyses the case of the musicians from the São Pedro Theatre Chamber Orchestra, located in Porto Alegre and run solely with private funding, showing that they survive exclusively on activities linked to the field of music through the fees received for playing the concerts and for their work providing other musical services. Through ethnographic research that included attending rehearsals and concerts, as well as interviews, it was possible to show how labour flexibilization affects the artists situated in this sector of the musical labour market.

\section{Palavras-chave}

Trabalho flexível; precarização; música erudita; profissão de músico; Orquestra de Câmara Theatro São Pedro de Porto Alegre.

Keywords

Flexible labor; job insecurity; classical music; musicians as a profession; Theatro São Pedro Chamber Orchestra of Porto Alegre. 